\title{
Development of a Unifying Target and Consensus Indicators for Global Surgical Systems Strengthening: Proposed by the Global Alliance for Surgery, Obstetric, Trauma, and Anaesthesia Care (The G4 Alliance)
}

Adil Haider ${ }^{1,2} \cdot$ John W. Scott $^{1,2} \cdot$ Colin D. Gause $^{3} \cdot$ Mira Meheš $^{4} \cdot$ Grace Hsiung $^{3} \cdot$ Albulena Prelvukaj $^{4}$. Dana Yanocha $^{4} \cdot$ Lauren M. Baumann $^{3} \cdot$ Faheem Ahmed $^{5} \cdot$ Na'eem Ahmed $^{5} \cdot$ Sara Anderson $^{6} \cdot$ Herve Angate $^{7}$. Lisa Arfaa $^{4} \cdot$ Horacio Asbun $^{8,9} \cdot$ Tigistu Ashengo $^{10,11} \cdot$ Kisembo Asuman $^{12} \cdot$ Ruben Ayala $^{13} \cdot$ Stephen Bickler $^{14}$. Saul Billingsley ${ }^{15} \cdot$ Peter Bird $^{16} \cdot$ Matthijs Botman $^{17} \cdot$ Marilyn Butler $^{18} \cdot$ Jo Buyske $^{19} \cdot$ Angelo Capozzi $^{20}$. Kathleen Casey $^{4} \cdot$ Charles Clayton $^{21} \cdot$ James Cobey $^{4,22} \cdot$ Michael Cotton $^{23} \cdot$ Dan Deckelbaum $^{24,25}$. Miliard Derbew $^{26} \cdot$ Catherine deVries $^{27} \cdot$ Jeanne Dillner $^{28} \cdot$ Max Downham $^{29} \cdot$ Natalie Draisin $^{15}$. David Echinard ${ }^{30} \cdot$ Sohier Elneil $^{31}$ - Ahmed EISayed ${ }^{32} \cdot$ Abigail Estelle $^{33} \cdot$ Allen Finley $^{34} \cdot$ Erica $^{3}$ Frenkel $^{35}$. Philip K. Frykman ${ }^{36}$ - Florin Gheorghe ${ }^{37} \cdot$ Julian Gore-Booth $^{38} \cdot$ Richard Henker $^{39} \cdot$ Jaymie Henry $^{4}$. Orion Henry $^{40}$ - Laura Hoemeke ${ }^{41}$ - David Hoffman ${ }^{42}$ - Iko Ibanga ${ }^{43}$ • Eric V. Jackson Jr. ${ }^{44}$ • Pankaj Jani ${ }^{26}$. Walter Johnson $^{45}$ - Andrew Jones ${ }^{46}$ - Zeina Kassem ${ }^{47}$ - Asuman Kisembo ${ }^{12}$ - Abbey Kocan ${ }^{48}$. Sanjay Krishnaswami ${ }^{49,50} \cdot$ Robert Lane $^{51} \cdot$ Asad Latif ${ }^{52} \cdot$ Barbara Levy $^{53} \cdot$ Dimitrios Linos $^{54,55} \cdot$ Peter Linz $^{56}$. Louis A. Listwa ${ }^{57} \cdot$ Declan Magee $^{58} \cdot$ Emmanuel Makasa $^{59} \cdot$ Michael L. Marin $^{60} \cdot$ Claude Martin $^{61}$. Kelly McQueen $^{62} \cdot$ Jamie Morgan $^{63} \cdot$ Richard Moser $^{64} \cdot$ Robert Neighbor $^{65} \cdot$ William M. Novick $^{66,67}$. $^{6}$ Stephen Ogendo $^{26} \cdot$ Akinyinka Omigbodun $^{68} \cdot$ Bisola Onajin-Obembe $^{69} \cdot$ Neil Parsan $^{70} \cdot$ Beverly K. Philip $^{71}$.

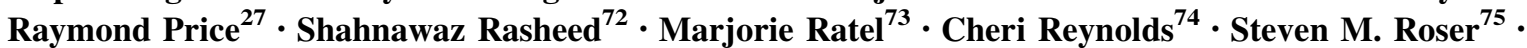
Jackie Rowles $^{76}$ - Lubna Samad ${ }^{77}$ - John Sampson ${ }^{78}$ - Harshadkumar Sanghvi ${ }^{11}$ - Marchelle L. Sellers ${ }^{79}$. David Sigalet $^{80} \cdot$ Bruce C. Steffes $^{81} \cdot$ Erin Stieber $^{82} \cdot$ Mamta Swaroop $^{83} \cdot$ John Tarpley $^{62} \cdot$ Asha Varghese $^{84}$. $^{8}$ Julie Varughese $^{85} \cdot$ Richard Wagner $^{86} \cdot$ Benjamin Warf $^{87} \cdot$ Neil Wetzig $^{88} \cdot$ Susan Williamson $^{89} \cdot$ Joshua Wood $^{90}$. $^{3}$ Anne Zeidan ${ }^{91} \cdot$ Lewis Zirkle $^{28} \cdot$ Brendan Allen $^{4} \cdot$ Fizan Abdullah $^{3,4}$

The original version of this article has been revised as reflected in the erratum: Dan Deckelbaum's family name was incorrect and Miliard Derbew's and Jamie Morgan's given names were incorrect.

Submitted on behalf of the Global Alliance for Surgical, Obstetric, Trauma, and Anaesthesia Care.

Fizan Abdullah

fabdullah@luriechildrens.org

Department of Surgery, Brigham and Women's Hospital, Boston, MA, USA

2 Center for Surgery and Public Health, Brigham and Women's Hospital, Boston, MA, USA

3 Division of Pediatric Surgery, Department of Surgery, Ann \& Robert H. Lurie Children's Hospital of Chicago, 225 East Chicago Ave, Box 63, Chicago, IL 60611, USA

4 The Global Alliance for Surgical, Obstetric, Trauma, and Anaesthesia Care, New York, NY, USA

5 Selfless, London, UK
ReSurge International, Sunnyvale, CA, USA

7 The Pan African Association of Surgeons, Parktown, Johannesburg, South Africa

8 Department of Surgery, Mayo Clinic Florida, Jacksonville, FL, USA

9 Society of American Gastrointestinal and Endoscopic Surgeons, Los Angeles, CA, USA

10 St. Paul Medical College, Addis Ababa, Ethiopia

11 Jhpiego, An Affiliate of Johns Hopkins University Baltimore, Baltimore, MD, USA

12 African Agency for Integrated Development, Kampala, Uganda

13 Operation Smile, Virginia Beach, VA, USA

14 Alliance for Surgery and Anaesthesia Presence, Lupsingen, Switzerland 
Abstract After decades on the margins of primary health care, surgical and anaesthesia care is gaining increasing priority within the global development arena. The 2015 publications of the Disease Control Priorities third edition on Essential Surgery and the Lancet Commission on Global Surgery created a compelling evidenced-based argument for the fundamental role of surgery and anaesthesia within cost-effective health systems strengthening global strategy. The launch of the Global Alliance for Surgical, Obstetric, Trauma, and Anaesthesia Care in 2015 has further coordinated efforts to build priority for surgical care and anaesthesia. These combined efforts culminated in the approval of a World Health Assembly resolution recognizing the role of surgical care and anaesthesia as part of universal health coverage. Momentum gained from these milestones highlights the need to identify consensus goals, targets and indicators to guide policy implementation and track progress at the national level. Through an open consultative process that incorporated input from stakeholders from around the globe, a global target calling for safe surgical and anaesthesia care for $80 \%$ of the world by 2030 was proposed. In order to achieve this target, we also propose 15 consensus indicators that build on existing surgical systems metrics and expand the ability to prioritize surgical systems strengthening around the world.

\section{Introduction}

Surgical care, encompassing surgery, obstetrics, trauma, and anaesthesia, is needed to address nearly one-third of the global burden of disease [1]. This need remains unmet for billions of people, as less than $6 \%$ of all surgeries are performed in the world's poorest countries, despite representing more than two-thirds of the world's population [2]. The majority of individuals in these low- and middle-

15 FIA Foundation, London, UK

16 AIC Kijabe Hospital, Kijabe County, Kenya

17 Netherlands Society for International Surgery, Amsterdam, The Netherlands

18 Global Pediatric Surgery Network, Portland, OR, USA

19 American Board of Surgery, Philadelphia, PA, USA

20 Rotaplast International, San Francisco, CA, USA

21 Primary Trauma Care Foundation, Oxford, UK

22 Johns Hopkins School of Public Health, Baltimore, MD, USA

23 International Collaboration for Essential Surgery, Angwin, CA, USA

24 Centre for Global Surgery, Montreal, QC, Canada

25 McGill University Health Centre, Montreal, QC, Canada

26 The College of Surgeons of East, Central and Southern Africa, Arusha, Tanzania

27 University of Utah Center for Global Surgery, Salt Lake City, UT, USA

28 SIGN Fracture International, Richland, WA, USA

29 International College of Surgeons, Chicago, IL, USA

30 HumaniTerra, Marseille, France

31 Fistula Foundation, San Jose, CA, USA

32 Alzaiem Alazhari University, Khartoum North, Sudan income countries (LMIC) do not have access to essential surgical care, with an estimated 143 million additional surgical procedures needed annually to bridge the gap [2]. People in resource-limited settings continue to suffer due to a lack of trained healthcare providers, inadequate health system infrastructure, disproportionate out-of-pocket healthcare costs, and a lack of prioritization of surgical care as part of national health plans [2,3]. With the recent approval of World Health Assembly (WHA) resolution

33 Willing and Abel, Norfolk, VA, USA

34 ChildKind International, Boston, MA, USA

35 Gradian Health Systems, Inc, New York, NY, USA

36 Global Pediatric Surgical Technology and Education Project, Irvine, CA, USA

37 Arbutus Medical Inc, Vancouver, Canada

38 World Federation of Societies of Anaesthesiologists, London, UK

39 American Association of Nurse Anesthetists, Park Ridge, IL, USA

40 Henry Family Advised Fund, Chicago, IL, USA

41 IntraHealth International, Chapel Hill, NC, USA

42 Healing the Children, Orlando, FL, USA

43 Pro-Health International, Edwardsville, IL, USA

44 Christiana Care Health System, Newark, DE, USA

45 WHO Global Initiative for Emergency and Essential Surgical Care, Geneva, Switzerland

46 Tropical Health and Education Trust, London, UK

47 Roads for Life, Beirut, Lebanon

48 Kupona Foundation, Saratoga Springs, NY, USA

49 World Journal of Surgery, Portland, OR, USA 
68.15 recognizing the importance of emergency and essential surgical care and anaesthesia as part of universal health coverage [4], and the introduction of the United Nations (UN) Post-2015 Sustainable Development Goals (SDGs) [5, 6], there is a critical need for consensus regarding strategies to support advocacy, resource mobilization, and strengthening of surgical systems as part of national healthcare plans worldwide.

The past 2 years have witnessed unprecedented engagement by academic, public health, government and multilateral organizations in advocating for the inclusion of safe surgical and anaesthesia care as part of the global health and policy agenda. Recent milestones include the publication of the World Bank Disease Control Priorities 3rd Edition (DCP3) Volume on Essential Surgery [7], and the Lancet Commission on Global Surgery (LCoGS) report that demonstrated a lack of access to surgery for 5 billion people worldwide [2]. In May 2015, the Global Alliance for Surgical, Obstetric, Trauma, and Anaesthesia Care (G4 Alliance) was officially launched as a coalition of 20 organizations dedicated to providing a voice for the billions of neglected surgical patients around the world [8]. Building on the pioneering efforts of numerous other groups, including the World Health Organization's (WHO) Global Initiative for Emergency and Essential Surgical

\footnotetext{
50 Oregon Health and Science University, Portland, OR, USA

51 International Federation of Surgical Colleges, Bogis-Bossey, Switzerland

52 Department of Anesthesiology and Critical Care Medicine, Johns Hopkins University, Baltimore, MD, USA

53 American College of Obstetricians and Gynecologists, Washington, DC, USA

54 Institute of Preventive Medicine, Environmental and Occupational Health - Prolepsis, Attica, Greece

55 National and Kapodistrian University, Athens Medical School, Athens, Greece

56 Mercy Ships, Lindale, TX, USA

57 Kenya Society of Anaesthesiologists, Nairobi, Kenya

58 Royal College of Surgeons of Ireland, Dublin, Ireland

59 Permanent Mission of the Republic of Zambia to the United Nations, Geneva, Switzerland

60 Mount Sinai Health System, New York, NY, USA

61 AO Alliance Foundation, Davos, Switzerland

62 Vanderbilt University Medical Center, Nashville, TN, USA

63 Physicians for Peace, Norfolk, VA, USA

64 Solidarity Bridge, Evanston, IL, USA

65 Diamedica UK Ltd, Devon, UK

66 University of Tennessee Health Science Center, Memphis, TN, USA
}

Care (GIEESC), the G4 Alliance serves to support WHO efforts and others by providing a much needed advocacy platform for the prioritization of surgical care as part of the global development agenda.

The DCP3 provides evidence on intervention efficacy and cost-effectiveness for the leading causes of the current global disease burden. The inclusion of a volume on essential surgery helped to define the avertable burden of surgically treatable disease and the potential impact of increasing access to surgical care to reduce the overall global disease burden. The LCoGS engaged individuals from over 110 countries to produce an evidence base and a compelling argument for investment in surgical care. In May 2015, the combined efforts of numerous organizations and stakeholders culminated in the unanimous approval by 194 WHO Member States of a WHA resolution dedicated to addressing the importance of surgical and anaesthesia care [4]. Resolution WHA68.15, "Strengthening emergency and essential surgical care and anaesthesia as a component of universal health coverage", issues a call to countries to adopt and implement policies that support prioritization and integration of safe, high-quality, and cost-effective surgical care and anaesthesia as part of existing health systems [4, 9, 10].

In only 24 months, the G4 Alliance has grown to become a network of over 80 organizations around the

67 William Novick Global Cardiac Alliance, Memphis, TN, USA

68 West African College of Surgeons, Lagos, Nigeria

69 Nigerian Society of Anesthetists, Lagos, Nigeria

70 Organization of American States, Washington, DC, USA

71 American Society of Anesthesiologists, Schaumburg, IL, USA

72 The Institute of Global Health Innovation, Imperial College London, London, UK

73 Korle-Bu Neuroscience Foundation, Langley, BC, Canada

74 Assist International, Scotts Valley, CA, USA

75 International Association of Oral and Maxillofacial Surgeons, Chicago, IL, USA

76 International Federation of Nurse Anesthetists, Sursee, Switzerland

77 Indus Hospital Pakistan, Karachi, Pakistan

78 Global Surgery Initiative, Johns Hopkins University, Baltimore, MD, USA

79 Mending Kids, Burbank, CA, USA

80 World Federation of Associations of Pediatric Surgeons, Geneva, Switzerland

81 Pan African Academy of Christian Surgeons, Linden, NC, USA

82 Smile Train, New York, NY, USA 


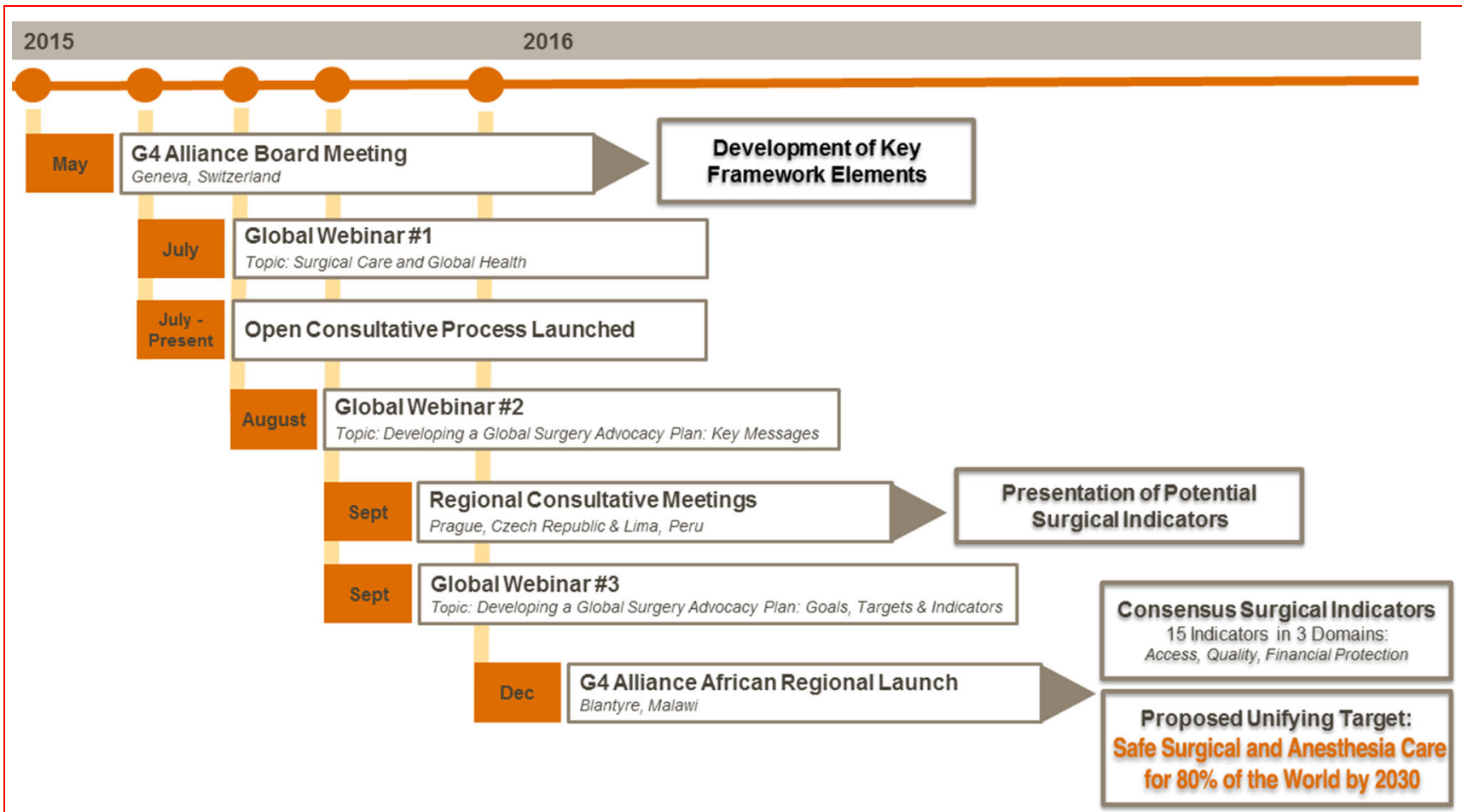

Fig. 1 Timeline of the global consultative process for the development of surgical indicators and the unifying target for safe surgical and anaesthesia care

world, including non-profit organizations, academic institutions, professional societies, federations, and private sector partners. The Alliance seeks to build political will and public health prioritization of surgical, obstetric, trauma, and anaesthesia care in support of WHA 68.15 as part of the global development agenda [4]. The G4 Alliance advances this goal through advocacy, policy implementation, and resource mobilization efforts. Its membership is purposefully diverse, with dues-paying member organizations in over 140 countries. Member organizations include experts in general surgery, obstetrics,

83 Association for Academic Surgery, Los Angeles, CA, USA

AmeriCares, Stamford, CT, USA

87

CURE International, Lemoyne, PA, USA

88 HEAL Africa, Gisengyi, Rwanda

89 Plasticos Foundation, Newport Beach, CA, USA

90 IVUmed, Salt Lake City, UT, USA

91 2nd Chance Association Reconstructive Surgery for Life Reconstruction, Meyrin, Switzerland trauma, anaesthesia, and other surgical specialties, as well as nursing, midwifery, and other non-physician surgical providers, disparate disciplines that have historically worked independent of one another yet are vital to strengthening surgical care. This manuscript describes the process and outcomes of a consensus building process that was used to develop a unifying target and consensus indicators for Global Surgical Systems Strengthening that has been approved by this very diverse alliance.

\section{Global consultation process}

The G4 Alliance implemented a global consultation process (Fig. 1) that includes the engagement of expert working groups to create consensus recommendations regarding global surgical care. While this consultative process is ongoing, recommendations have already emerged, including (1) the importance of developing a framework of multidisciplinary and cross-cutting metrics that reflect the critical role of surgical, obstetric, trauma, and anaesthesia care services at the first-referral level, and (2) the need for coordinated global targets to provide specific, time-bound and actionable objectives that will guide the response of global stakeholders. Similar strategies have been successfully employed by other global health movements [11]. 


\section{Development of the G4 alliance platform}

\section{Development of surgical indicators and global targets}

Key outputs from the G4 Alliance's consultative process include cross-disciplinary goals, targets, and indicators as well as a framework of international standards and guidelines that can be adapted to local and regional contexts. This consultative process began with the establishment of an expert working group on goals, targets, and indicators. This group first defined the primary purpose of surgical indicators: (1) to serve as tools for advocacy, quality, and patient-centred care at the local, national, and international level; (2) to guide decision making around surgical services at the local and national level; and (3) to assist fundraising and resource mobilization efforts by demonstrating existing needs and goal-oriented progress over time.

In addition, the working group established that all indicators considered in the process must: (1) build and strengthen existing initiatives, especially building upon established priority indicators put forth by the LCoGS [2], the WHO's Core 100 List of Health Indicators [12], the World Bank's World Development Indicators (WDIs) [13], and the UN SDGs [5]; (2) be practical and feasible to collect; (3) be applicable at the international, national, and regional levels; (4) contribute to the G4 Alliance's aim to collectively represent diverse socioeconomic and multidisciplinary stakeholders invested in improving surgical care; and (5) support a unifying target to help align global efforts.

Establishing consensus surgical indicators began with a detailed review of existing repositories of health indicators, including the LCoGS [2], WHO's Core 100 List of Health Indicators [12], World Bank's WDIs [13], UN SDGs [5], and indicators utilized in other global health advocacy efforts [11]. During this review, it was noted that these groups had already done exceptional work. In particular, the six indicators proposed by the LCoGS for surgical systems strengthening were extremely relevant and timely. It was additionally felt that there was a need to add indicators that also synergistically represented obstetric, trauma, and anaesthesia care along with those for surgery in order to create a more nuanced picture of a health system's surgical and anaesthesia care capacity. Thus, the working group began with the six core surgical indicators established by the LCoGS [2] and then incorporated additional metrics that reflect the synergistic role of providing surgical, obstetric, trauma, and anaesthesia care. As part of this process, the G4 Alliance hosted three global webinars throughout 2015, bringing together multidisciplinary content experts, member organizations, and members of the general public. Additionally, specific input was sought from expert stakeholders from across disciplines of surgical, obstetric, trauma, and anaesthesia care.

Initial recommendations were consolidated by the working group and presented during G4 Alliance regional consultative meetings held in Prague, Czech Republic, during the International College of Surgeons Jubilee World Congress, and during the Confederation of Latin American Societies of Anaesthesiologists Congress (CLASA; the World Federation of Societies of Anesthesiologists' Latin American Regional Section) in Lima, Peru, both in September 2015. Emerging ideas were introduced and debated by attendees during these regional meetings, helping the working group to achieve a consensus. A summary of the consultative process is included in Fig. 1 .

A preliminary set of consensus indicators and a proposed unifying global target were introduced at the G4 Alliance's Board Meeting, African Regional Launch Event and Consultation held in Blantyre, Malawi, in December 2015. During these meetings, proposed consensus indicators were introduced, debated, and refined in breakout sessions and plenaries. After a period of public reporting and open discussion, the list of 15 consensus surgical indicators for global surgical, obstetric, trauma, and anaesthesia care (Table 1) was established, along with a global unifying target. This list is comprised of the six core surgical indicators from the recent LCoGS [2], as well as nine other multidisciplinary surgical indicators previously established by either the WHO or other professional associations [12, 14-17]. The multidisciplinary framework of the 15 consensus indicators includes three key domains: access, quality, and financial risk protection. While each indicator provides unique information, they are purposefully interdependent and designed to be implemented and monitored as part of a complete surgical care package.

\section{Consensus surgical care indicators}

Throughout this consultative process, there was significant discussion regarding the need to balance the adoption of key indicators of surgical care with the burden of implementation and national-level data collection. Collecting these surgical indicators requires a dedicated workforce and a process by which governments can receive sustainable support for the collection and analysis of data. This process requires manpower and resources, representing potential hurdles to tracking and reporting. Fortunately, many of these indicators are currently being collected, decreasing the burden on national health systems.

\section{Access to surgical care}

The first two indicators include access to timely essential surgery and specialist surgical workforce density. In 
Table 1 Proposed indicators to monitor and evaluate surgical systems

\begin{tabular}{|c|c|c|c|}
\hline Domain & Best for & Indicator & Reference \\
\hline \multirow[t]{7}{*}{ Access } & \multirow[t]{2}{*}{ Surgical system } & Access to timely essential surgery ${ }^{\dagger}$ & $\begin{array}{l}\text { WHO Core } \\
100^{* *}\end{array}$ \\
\hline & & Specialist surgical workforce density ${ }^{\dagger}$ & $\begin{array}{c}\text { WHO Core } \\
100^{* *}\end{array}$ \\
\hline & Trauma care & Estimated proportion of seriously injured patients transported by ambulance & WHO IMR \\
\hline & $\begin{array}{c}\text { Trauma and } \\
\text { obstetrics }\end{array}$ & National whole blood donation rate & WHO GDBS \\
\hline & Obstetrics & C-section rate & $\begin{array}{c}\text { WHO Core } \\
100+\end{array}$ \\
\hline & \multirow[t]{2}{*}{ Anaesthesia } & Proportion of operating theatres with pulse oximetry & WHO PSPOP \\
\hline & & Ratio of anaesthetists to surgeons & $\begin{array}{l}\text { WHO Core } \\
100^{* *}\end{array}$ \\
\hline \multirow[t]{6}{*}{ Quality } & \multirow[t]{2}{*}{ Surgical system } & Surgical Volume ${ }^{\dagger}$ & $\begin{array}{l}\text { WHO Core } \\
100^{* *}\end{array}$ \\
\hline & & Perioperative mortality rate $(\mathrm{POMR})^{\dagger}$ & WHO Core 100 \\
\hline & Trauma care & Inpatient trauma mortality rate & ACS COT \\
\hline & \multirow[t]{2}{*}{ Obstetrics } & $\begin{array}{l}\text { Maternal Mortality Ratio (proportion due to maternal haemorrhage, obstructed } \\
\text { labour) }\end{array}$ & $\begin{array}{c}\text { WHO Core } \\
100^{* *}\end{array}$ \\
\hline & & Neonatal mortality & WHO Core 100 \\
\hline & Anaesthesia & POMR on operative day & $\begin{array}{l}\text { WHO Core } \\
100^{* *}\end{array}$ \\
\hline \multirow[t]{2}{*}{$\begin{array}{c}\text { Financial risk } \\
\text { protection }\end{array}$} & \multirow[t]{2}{*}{ Surgical system } & Protection against impoverishing expenditure ${ }^{\dagger}$ & $\begin{array}{l}\text { WHO Core } \\
100^{* *}\end{array}$ \\
\hline & & Protection against catastrophic expenditure ${ }^{\dagger}$ & $\begin{array}{l}\text { WHO Core } \\
100^{* *}\end{array}$ \\
\hline
\end{tabular}

$\uparrow^{\dagger}$ Core LCoGS measure for surgical systems strengthening, WHO Core 100: Worth Health Organization's Global Reference List of 100 Core Health Indicators, 2015, WHO Core 100** the surgically relevant indicator can be disaggregated from existing Core 100 indicators, WHO Core 100+ signifies a Core 100 “Additional Indicator”, WHO IMR: WHO's Indicator and Measurement Registry, WHO GBDS: WHO's Global Database on Blood Safety, WHO PSPOP: WHO's Patient Safety Pulse Oximetry Project, ACS COT: American College of Surgeons Committee on Trauma

accordance with the LCoGS and the WHO Core 100, timely access is defined as the proportion of the population that live within 2-h travel time to a facility that can provide services including caesarean section, laparotomy, long bone fracture repair and cranial surgery, while surgical workforce density is defined as the number of trained surgeons, anaesthetists, and obstetricians per 100,000 population $[2,12]$. Taken together, these two populationlevel indicators provide an overall measure of the availability of a basic level of surgical care.

The estimated proportion of seriously injured patients transported by ambulance and the caesarean section (Csection) rate provide a more complete understanding of access to trauma and obstetric care [12, 14]. Previously used as a proxy for timely access to trauma care [18], the proportion of injured patients transported by ambulance is an important access measure which has been established as a "pillar indicator" by the UN's Road Safety Collaboration and the WHO [19]. In the 2015 Statement on Caesarean Section Rates [20], the WHO affirms the live-saving role of $\mathrm{C}$-sections, when indicated. While rates above $10 \%$ have not been linked to reductions in maternal and newborn mortality rates [20], tracking the $\mathrm{C}$-section rates is critical to identify both insufficient access and overuse. Critical for all surgical patients, the WHO report on blood safety highlights the "major imbalance between developing and developed countries in the level of access to safe blood" with a median national whole blood donation rate of 36.4 donations/1000 population in HICs versus 2.8 in LICs [21]. As such, national whole blood donation rate provides an important proxy for both resource availability and systems development [15].

Anaesthesia is essential to safe and pain-free surgery and represents a major contributor to positive outcomes after any intervention [22]. Access to safe anaesthesia care underpins any surgical care delivery system and can be monitored by tracking the ratio of anaesthetist to surgeon and the proportion of operating theatres with pulse oximetry [16]. Tracking and improving the ratio of anaesthetist to surgeon is necessary to address the critical lack of trained anaesthesia providers globally [23]. Additionally, the proportion of operating theatres with pulse 
oximetry, previously established as a marker for the availability of essential surgical equipment [24], is critical to providing safe surgical and anaesthesia care. Notably, up to $70 \%$ of district hospitals in sub-Saharan Africa do not have pulse oximetry available [25], further underscoring the importance of implementing this measure. These proxy measures correlate with access in terms of both human and material resources and provide a more detailed description of the distribution and availability of safe anaesthesia.

\section{Surgical care quality}

The G4 Alliance joins others in promoting perioperative mortality rate (POMR) as a fundamental quality metric for surgery $[2,12]$. Defined as death on the day of surgery, death before discharge, or death within 30 days of procedures, POMR is a feasible, credible, and critical measure of surgical quality $[2,13,25,26]$. As case mix and volume are integrally related to mortality risk, POMR should be considered in the context of overall surgical volume, measured in cases per 100,000 population $[2,12]$. While day of surgery mortality may be secondary to a myriad of causes including severity of patient's illness, case complexity, intraoperative decision making, and resource availability, it may also reflect the quality of anaesthesia care. Documenting the presence of untreated head injury as part of the multi-trauma patient population will inform the POMR in the presence of unavailable timely imaging and surgical resources. Areas without the capacity to provide high-quality, safer anaesthesia care will have a much higher perioperative mortality rate within $24 \mathrm{~h}$ of surgery. Additionally, day of surgery POMR will provide more much meaningful information regarding the safety of anaesthesia care than will 30-day POMR. As such, longitudinal tracking of day of surgery POMR can provide important insight into the safety of anaesthesia care $[2,12,22]$. Although these measures may be coarse, they serve as a requisite starting point for any surgical system seeking to improve the quality of care delivery.

The current standard for assessing quality of trauma care is the inpatient trauma mortality rate [17, 27]. When viewed alongside the trauma-related access measure of proportion of injured patients receiving ambulance transport, these two indicators provide an overall sense of both access to and quality of trauma care. Similarly, the quality of obstetric care is determined by not only access to caesarean section, but by the maternal mortality ratio (MMR), with specific attention paid to the proportion of MMR related to surgically amenable causes such as maternal haemorrhage and obstructed labour [12]. Often used to interpret the benefit of population-level access to C-sections [28], Neonatal mortality rate $^{1}$ represents another

\footnotetext{
${ }^{1}$ Number of deaths before 28 days of age per 1000 births.
}

important indicator related to timely access to safe surgical care. Taken together, these two indicators are crucial to the development of a surgical system that can significantly impact both maternal and child health care.

\section{Financial risk protection}

Findings from the LCoGS suggest that approximately 33 million people worldwide face catastrophic health expenditures each year, directly attributable to costs related to surgical services [2]. When factoring in non-medical costs, this estimate increases to 81 million people [2]. Simply put, there is no quality without access, and there is no access if millions of individuals cannot afford essential surgical services. As such, the G4 Alliance promotes the use of indicators to measure protection against catastrophic expenditure $^{2}$ as well as protection against impoverishing expenditure $[2,12]{ }^{3}$. These measures are calculated as the proportion of households that are protected from either catastrophic or impoverishing expenditures due to direct out-of-pocket costs of surgical care.

\section{Monitoring surgical indicators}

The proposed surgical indicators (Table 1) rely on established indicators that can serve as a proxy for systems capacity rather than disease-specific clinical data. We recommend that health systems conduct routine and standardized collection of data to allow comparisons over time and between locations. Routine assessments of burden further allow for advocacy around prioritization of specialty care as a part of the overall surgical community, with indicators specific to a disease or condition (Table 2). Such assessments will allow national health organizations to focus on areas of need within the broader field of surgical care itself, including specialty disciplines.

\section{Unifying global target}

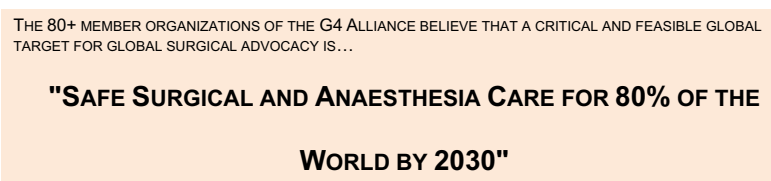

The indicator framework is designed to measure the ability of a health system to provide safe, high-quality, accessible surgical care. Demonstrating sustained progress across these interdependent indicators is critical to achieve universal access to high-quality surgical, obstetric, trauma, and anaesthesia care. After consensus consideration, the G4

\footnotetext{
${ }^{2}$ Expense that exceeds $40 \%$ of annual post-subsistence income.

${ }^{3}$ Expense that causes a household to fall below the poverty line.
} 
Table 2 Proposed indicators to monitor sub-specialty care

\begin{tabular}{ll}
\hline Burden & Population-level incidence and prevalence measures \\
& DALYs attributed to condition; proportion of DALYs avertable by treatment \\
Access & Proportion of population able to access facilities providing condition-specific care \\
& Sub-specialist providers per 100 K population \\
Quality & Annual volume of sub-specialty procedures \\
& Post-operative mortality/morbidity \\
Financial protection & Inclusion into national insurance coverage \\
& Protection against impoverishing and catastrophic expenditure \\
\hline
\end{tabular}

Alliance established its unifying global target as "Safe Surgical and Anaesthesia Care for $80 \%$ of the World by 2030". This global target is meant to be applied at the global, national, and subnational level, incorporating the interdependent nature of access, quality, and universal health coverage. As up to 5 billion people currently lack access to safe surgical care [2], urgent action is required worldwide to meet the critical needs of the neglected surgical patient.

\section{The way forward}

The G4 Alliance and its member organizations are committed to achieving the global goal of "safe surgical and anaesthesia care for $80 \%$ of the world by 2030 ". The proposed 15 consensus indicators were chosen so that we can critically monitor and evaluate efforts, as we collectively create a path towards this goal. These consensus indicators integrate the collective interests of surgery, obstetrics, trauma, and anaesthesia by providing interdependent measures of access, quality, and financial risk protection. They have been purposefully drawn from existing indicators, which will facilitate monitoring and evaluating ongoing surgical systems strengthening efforts. Ultimately, their collective adoption will be critical to effective implementation of safe surgical systems for the world's neglected surgical patients.

Immediate action is required to translate academic, political, and advocacy efforts into tangible, effective implementation of surgical care delivery. As an initial step, countries are encouraged to develop national surgical plans (NSPs) to assess their own strengths, weaknesses, needs, and goals regarding safe and effective surgical care delivery. It is reassuring to note that in response to the LCoGS nearly a dozen countries are already beginning to develop NSPs, which is a very welcome occurrence. Many of these countries are being assisted by the LCoGS and are focusing their initial indicator data collection on the six core LCoGS indicators for surgical systems. In addition, the World Bank is considering inclusion of these core measures in their World Development Indicators, which will make their collection even more sustainable and durable. As an alliance, we applaud these initial efforts and believe that collection of these six core indicators will lay the groundwork for the collection and utilization of the broader 15 consensus indicators presented in Table 1. (The six core indicators mentioned above are included within these 15 consensus indicators.) Indicators are critical components to guide both the development and the monitoring of progress within a national surgical plan. As these plans begin to emerge, collection and monitoring of indicators may vary based on individual country circumstances. For reasons of sustainability and feasibility, many may choose to begin data collection with a more limited set such as the six core surgical indicators proposed by LGoGS. This is understandable, and we agree that at a minimum, all NSPs should include collection of these measures. However, as an alliance we strongly recommend countries to quickly develop the capability to gather and utilize all 15 of the consensus indicators presented in this document so that a more complete understanding of a nations' Surgery, Anaesthesia, Trauma, and Anaesthesia care can be ascertained and responded to. Continued collaboration throughout the surgical community is needed to establish best practices to support development of NSPs for countries in critical need of surgical systems strengthening.

Moving forward, consensus indicators must be incorporated into a new global accountability framework for surgical care, which will allow clinicians, governments, funders, local and international organizations to unite around common goals and targets, and track progress over time. This framework is needed to expand upon the key messages championed by the DCP3, the LCoGS, WHO GIEESC, and the G4 Alliance [2, 7, 8] and promote international standards and guidelines to evaluate health systems improvements. An agile data platform is also needed to help avoid siloed efforts and improve economies of scale through interconnectivity and alignment of goals and stakeholders, while tracking developments in clinician training standards as well as ongoing partnerships.

Building consensus for indicators and global targets represents an essential step towards developing a global accountability framework for surgical care, as a critical 
component of health, human rights, and economic growth. Revisiting the call to action shared by Dr. Hafdan Mahler, WHO Director General in 1980, these efforts are important to ensure that "surgery will play its proper role in bringing the people of the world nearer to the goal of health for all..." [29] Surely by achieving safe surgical and anaesthesia care for $80 \%$ of the world by 2030 , we will be closer to achieving this goal for humanity.

Open Access This article is distributed under the terms of the Creative Commons Attribution 4.0 International License (http://crea tivecommons.org/licenses/by/4.0/), which permits unrestricted use, distribution, and reproduction in any medium, provided you give appropriate credit to the original author(s) and the source, provide a link to the Creative Commons license, and indicate if changes were made.

\section{References}

1. Shrime MG, Bickler SW, Alkire BC, Mock C (2015) Global burden of surgical disease: an estimation from the provider perspective. Lancet Glob Health. 3(Suppl 2):S8-S9

2. Meara JG, Leather AJ, Hagander L et al (2015) Global Surgery 2030: evidence and solutions for achieving health, welfare, and economic development. Lancet 386(9993):569-624

3. Mock C, Donkor P, Gawande A, Jamison DT, Kruk ME, Debas HT (2015) Essential Surgery: Key Messages of this Volume. In: Debas HT, Donkor P, Gawande A, Jamison DT, Kruk ME, Mock CN (eds) Disease control priorities, Third Edition (Volume 1): essential surgery. World Bank Publications, Washington

4. World Health Association (2015) World Health Assembly Resolution 68.15: Strengthening emergency and essential surgical care and anaesthesia as a component of universal health coverage. Sixty-Eight World Health Assembly. http://apps.who.int/gb/ ebwha/pdf_files/WHA68/A68_R15-en.pdf

5. United Nations (2015) Sustainable Development Knowledge Platform: Sustainable Development Goals. https://sustaina bledevelopment.un.org/sdgs

6. The Global Goals for Sustainable Development (2015). http:// www.globalgoals.org/

7. Mock C, Donkor P, Gawande A, Jamison D, Kruk M, Debas H (2015) Disease control priorities, third edition (Volume 1): essential surgery. World Bank Publications, Washington

8. The Global Alliance for Surgical, Obstetric, Trauma, and Anaesthesia Care. http://www.theg4alliance.org, 2015

9. Mock C (2015) A banner year for global surgery: now how to make it make a difference on the ground. World J Surg 39(9):2111-2114. doi:10.1007/s00268-015-3154-x

10. Price R, Makasa E, Hollands M (2015) World Health Assembly Resolution WHA68.15: "Strengthening Emergency and Essential Surgical Care and Anaesthesia as a Component of Universal Health Coverage"-Addressing the Public Health Gaps Arising from Lack of Safe, Affordable and Accessible Surgical and Anesthetic Services. World J Surg 39(9):2115-2125. doi:10. 1007/s00268-015-3153-y

11. The Non-Communicable Disease Alliance, NCD Alliance Report 2009-2011. https://ncdalliance.org/sites/default/files/resource_ files/NCD\%20Alliance\%20Report\%202009\%20-\%202011.pdf

12. World Health Organization. Global Reference List of 100 Core Health Indicators, Working Version 5. http://www.who.int/healthinfo/ country_monitoring_evaluation/GlobalRefListCoreIndicators_
V5_17Nov2014_WithoutAnnexes.pdf. Accessed March 11, 2016

13. The World Bank (2015) World Development Indicators. Washington, D.C.: http://data.worldbank.org/data-catalog/world-devel opment-indicators

14. World Health Organization. Estimated \% of Seriously Injured Patients Transported by Ambulance. Indicator and Measurement Registry version 1.7.0. http://apps.who.int/gho/indicatorregistry/ App_Main/view_indicator.aspx?iid=3358. Accessed March 11, 2016

15. World Health Organization. Global Database on Blood Safety: Summary Report 2011. http://www.who.int/bloodsafety/global_ database/GDBS_Summary_Report_2011.pdf. Accessed March 11,2016

16. World Health Organization. Patient Safety and Pulse Oximetry Project. http://www.who.int/patientsafety/safesurgery/pulse_oxi metry/en/. Accessed March 11, 2016

17. American College of Surgeons. Optimal Care of the Injured Patient 2014. https://www.facs.org/ /media/files/quality\%20pro grams/trauma/vrc\%20resources/resources\%20for\%20optimal\% 20care\%202014\%20v11.ashx. Accessed March 11, 2016

18. Alkire BC, Raykar NP, Shrime MG et al (2015) Global access to surgical care: a modelling study. Lancet Glob Health. 3(6):e316e323

19. World Health Organization. Monitoring and evaluating the Decade of Action for Road Safety 2011-2020. Monitoring and evaluating the Decade of Action for Road Safety: Report from the Working Group of the UNRSC. http://www.who.int/roadsafety/ decade_of_action/monitoring/UNRSC_M_and_E_Report_Version_ 3.pdf?ua=1. Accessed 9 April 2016

20. World Health Organization. World Health Organization Statement on Caesarean Section Rates. http://apps.who.int/iris/bit stream/10665/161442/1/WHO_RHR_15.02_eng.pdf. Accessed April 9, 2016

21. World Health Organization. Blood Safety Fact Sheet. http://www. who.int/worldblooddonorday/media/who_blood_safety_factsheet_ 2011.pdf. Accessed April 9, 2016

22. World Federation of Societies of Anaesthesiologists. http://www. wfsahq.org/. Accessed March 21, 2016

23. Dubowitz G, Detlefs S, McQueen KA (2010) Global anaesthesia workforce crisis: a preliminary survey revealing shortages contributing to undesirable outcomes and unsafe practices. World J Surg 34(3):438-444. doi:10.1007/s00268-009-0229-6

24. Funk LM, Weiser TG, Berry WR et al (2010) Global operating theatre distribution and pulse oximetry supply: an estimation from reported data. Lancet 376(9746):1055-1061

25. Walker IA, Obua AD, Mouton F, Ttendo S, Wilson IH (2010) Paediatric surgery and anaesthesia in south-western Uganda: a cross-sectional survey. Bull World Health Organ 88(12):897-906

26. Watters DA, Hollands MJ, Gruen RL et al (2015) Perioperative mortality rate (POMR): a global indicator of access to safe surgery and anaesthesia. World J Surg 39(4):856-864. doi:10.1007/ s00268-014-2638-4

27. Ardolino A, Sleat G, Willett K (2012) Outcome measurements in major trauma-results of a consensus meeting. Injury 43(10):1662-1666

28. Ye J, Betran AP, Guerrero Vela M, Souza JP, Zhang J (2014) Searching for the optimal rate of medically necessary cesarean delivery. Birth. 41(3):237-244

29. Mahler H. Address to the XII Biennial World Congress of the International College of Surgeons. June 29, 1980; Mexico City, Mexico 